Western University

Scholarship@Western

FIMS Publications

Information \& Media Studies (FIMS) Faculty

2018

Information World Mapping to Explicate the Information- Care Relationship in Dementia Care

Nicole K. Dalmer

The University of Western Ontario,ndalmer@uwo.ca

Follow this and additional works at: https://ir.lib.uwo.ca/fimspub

Part of the Library and Information Science Commons

Citation of this paper:

Dalmer, N. (2017). Information World Mapping to Explicate the Information-Care Relationship in Dementia Care. ASIS\&T 54, 1, 1-3. 


\title{
Information World Mapping to Explicate the Information- Care Relationship in Dementia Care
}

\author{
Nicole Dalmer \\ Faculty of Information and Media Studies \\ The University of Western Ontario, London, Ontario, Canada \\ ndalmer@uwo.ca
}

\begin{abstract}
Information world mapping is a helpful data elicitation technique to make visible the hidden work of finding, using and making sense of information. This methods-based paper explores the utility of a mapping exercise both within an institutional ethnographic study and in eliciting informants' understandings and descriptions of their care-related information work. Eleven family caregivers of communitydwelling older adults living with dementia drew maps of their information worlds. Each map depicts a unique combination of information resources (people, agencies, texts and websites) accessed, relationships that shape the information work in addition to key locations frequented to access information. Given the difficulty in delineating the boundaries of information, the mapping exercise served as a helpful tool for caregivers to make visible the intricacies of their information work, including the barriers encountered and inventive strategies created to access, use and translate information needed to guide and support their care work.
\end{abstract}

\section{Keywords}

Dementia, family caregivers, information work, institutional ethnography, information worlds

\section{INTRODUCTION}

As the proportion of older adults will more than double in the next 20 years (Statistics Canada, 2010), the aging of Canada's population necessitates innovative supports from familial, societal and governmental institutions. The federal government's endorsement of aging in place (the ability to live at home for as long as possible) combined with a shifting away from institutionalization and decreasing availability of government-funded home care programs is increasingly transferring responsibilities and demands for unpaid care work onto families. Of particular interest for this study are the implications of aging in place for people living with dementia, the most significant cause of disability among Canadians over the age of 65, affecting nearly 747,000 Canadians, a number expected to double by 2031 (Alzheimer Society of Canada, 2012).

ASIS\&T 2017, Washington, DC | Oct 27-Nov 1, 2017

[Author Retains Copyright]
The information work that informs and guides care is one invisible and unrecognized form of work done by family caregivers. The provision of, access to, and ability to navigate and use information enables family caregivers to be involved in the care and wellbeing of aging family members. With access to an increasing wealth of health and carerelated information, increasing responsibility is being passed "to individuals, with their effectiveness determined by their ability to gather, then intelligently act on, health information" (Johnson \& Case, 2012, p. 5). This expectation that family caregivers will 'do' information work is confounded, however, by a significant number of studies "indicating that extensive unmet caregiver information needs persist" (Washington, Meadows, Elliott, \& Koopman, 2011, p. 39).

The act of searching for information on behalf of another (such as a family carer searching for or on behalf of an older adult in their care) represents an especially underarticulated and complex form of work as "the information-seeking work involved in taking responsibility for one's ... family members' health involves much more than simply looking for and locating data relevant to a specific condition ... it means sifting through, interpreting and dealing with the implications of the information one finds" (Harris, 2009, p. 78). Barnes and Henwood (2015) critique the 'informatization of care', a trend in which information may marginalize or replace care. These authors draw attention to the distinction between informing to care and informing with care; the latter indicative that information is neither separate nor outside care, but is instead inextricably linked to care (p. 159).

Corbin and Strauss (1985) first described 'information work' as a form of work done by people living with chronic illness. Within library and information science (LIS), Hogan and Palmer (2005) and Souden (2008) have taken up the concept, both characterizing information-related activities as part of the work of managing one's own chronic illness. This present study aims to advance the conceptualization of information work by focusing on the additional work of searching on behalf of or because of another. In alignment with Corbin and Strauss (1985), I assert that care work "has an information component and presumes some degree of information processing whether the work is manual labor or highly abstract decision making" (Huvila, 2009, p. 3). 
Characterizing caregivers' information practices as work brings attention to the time, effort, resources, etc. that are often made invisible in literature and policy, owing to the construction of caregiving as a gendered concept of social and familial responsibility.

\section{FRAMEWORK OF INQUIRY}

Originating in the 1970s by Canadian sociologist Dorothy E. Smith, institutional ethnography (IE) is a method of inquiry that maps how the everyday world of people's experiences are "put together by relations that extend vastly beyond the everyday" (Smith, 2005, p. 1). While rooting itself in individuals' knowledge and the actualities of their everyday experiences, this method of inquiry simultaneously acknowledges that these every day, local experiences are permeated and coordinated by relations, decisions and institutions that are outside of and may be invisible to those living in their local environments. Mapping and making known these relations that extend beyond the local and the everyday is the crux of institutional ethnography. While notably implemented in education, nursing and other professional and service-oriented fields, as Stooke and McKenzie (2009) observe, institutional ethnography is not yet "widely taken up by library and information science researchers" (p. 660).

\section{STUDY DESCRIPTION}

Eleven family caregivers of community-dwelling older adults living with dementia were interviewed about their information-related care work. Caregivers ranged in age from 58 to 73 years of age and represented a variety of relationships to the care recipient: wife, husband and daughter. The older adults living with dementia receiving care ranged in age from 67 to 87 years of age and had diagnoses of Alzheimer's disease, early-onset Alzheimer's, Parkinson's-disease dementia, mixed dementia and Frontotemporal dementia. For the interview process, work, and more specifically, work knowledges focused the interview conversation, with the intention to ground interviews in the accounts of caregivers' everyday activities. To complement the caregivers' reported experiences, in response to the mapping metaphor that runs throughout the IE method of inquiry, informants were asked to map out the information work they described in the earlier interview. Caregivers were given a large degree of control over the design and interpretation of their information worlds. In addition to items, places, and relationships that might shape or guide their information work, informants were encouraged to include social context, including what they might do with information once it was found.

This mapping activity is based on the concept of Sonnenwald's information horizons (1999) and builds on subsequent mapping exercises outlined by Greyson, O'Brien and Shoveller (2017), and Freund, Hawkins and Saewyc (2016). An information horizon is created within a context and a situation and is determined individually and socially in which any number of information resources may be contained. While caregivers' information work may occur in a broader, more generalizable context or situation than that prescribed by Sonnenwald, this concept served as a useful framework for understanding caregivers' experiences of their information work. Informants were asked to talk out loud as they created their unique world (Sonnenwald, 1999). Prompting questions included asking informants why they drew their map in a certain order or why items mentioned in the interview did not appear on the map (or conversely, what items appeared on the map that were not discussed throughout the interview). Following the completion of a pilot study, a template information world was created so that informants could choose to work from a blank paper or from the template, which made the mapping exercise less onerous.

\section{RESULTS}

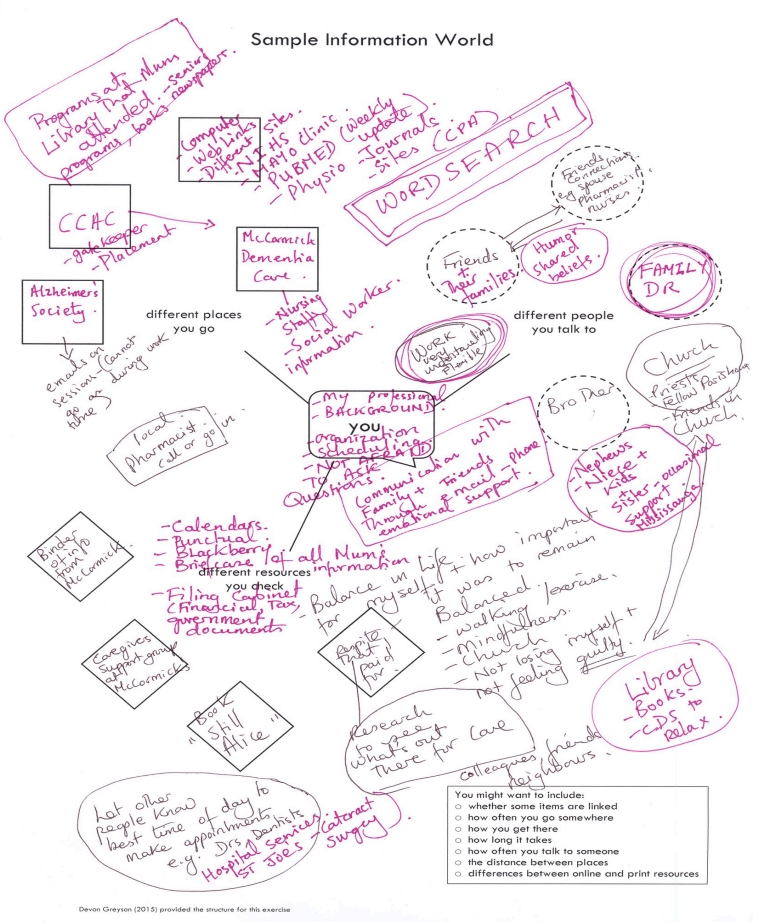

Figure 1. Catherine's Information World

As exemplified in Figure 1, each map depicts the caregiver's unique interpretations of their work, representing the information resources (family members, health care professionals, agencies, texts, tools and websites) they accessed within their care context. In addition to mapping information sites and resources, caregivers included relationship dynamics, quotes and self-care activities, indicating how information more broadly intersects with and may both support and complicate their care work. A majority of caregivers were eager to participate in this exercise and the mapping exercise served as a memory aid, eliciting a discussion of a number of information activities not mentioned in the interview. As the informants completed the mapping exercise, they noted that they were both surprised and validated by the work they had done. The mapping 
exercise made visible, to them, the amount and the different types of work that they have performed throughout their caregiving trajectory. While each world was distinct, commonalities observed between the information worlds included the degree to which relationships shaped and modulated the amount and the type of information shared. Informants also drew how their own background, education and personality traits have come to shape their information work.

\section{CONCLUSIONS}

Good care is often positioned as a natural by-product of the widespread availability of good information. As the information world maps reveal, however, information work is not separate or outside of care, but is instead inextricably linked to care work and involves mobilizing and negotiating different types of information depending on the situation, the timing, the contexts or the different individuals involved.

The use of institutional ethnography to approach the information world mapping exercise privileges the everyday work of family caregivers of community-dwelling older adults living with dementia. IE also attunes the analysis of each map to the work, and more specifically, the information-related care work that is often invisible, permitting a more holistic view of the role of information as caregivers navigate spaces, agencies, resources, tools and other individuals throughout their everyday lives.

As the concept of information work is still in flux, the mapping exercises suggest some amendments to consider as a means to continue to make the work of finding, using, sharing and managing information more visible; building a concept of information work that goes beyond purposive, conscious and intended actions, but instead allows for the incorporation of information avoidance as work, that acknowledges the complex work of searching on behalf of or for another, the work of information storage and management, and the affective or emotional components of information activities that may be relationally influenced. If we allow for more nuanced understandings of the complexities of information practices, we may be able to move from informing to treat to informing to care.

\section{ACKNOWLEDGMENTS}

I am humbled by and indebted to those informants who so openly and willingly shared their experiences. This research is supported by the Social Sciences and Humanities Research Council of Canada.

\section{REFERENCES}

Alzheimer Society of Canada. (2012). A new way of looking at the impact of dementia. Retrieved from http://www .alzheimer.ca/ /media/Files/national/Mediareleases/asc_factsheet_new_data_09272012_en.pdf

Barnes, M., Henwood, F., \& Smith, N. (2016). Information and care: A relational approach. Dementia, 15(4), 510525 .
Corbin, J., \& Strauss, A. (1985). Managing chronic illness at home: Three lines of work. Qualitative Sociology, 8(3), 224-247.

Freund, L., Hawkins, B., \& Saewyc, E. (2016). Reflections on the use of participatory mapping to study everyday health information seeking by LGBTQ youth. Proceedings of the American Society for Information Science and Technology, 53(1).

Greyson, D., O'Brien, H., \& Shoveller, J. (2017). Information world mapping: A participatory arts-based elicitation method for information behavior interviews. Library \& Information Science Research, 39(2), 149-157.

Harris, R. (2009). Cyber-burdens: Emerging imperatives in women's unpaid care work. In E. Balka, E. Green \& F. Henwood (Eds.), Gender, health and information technology in context (pp. 72-87). New York: Palgrave Macmillan.

Hogan, T. P., \& Palmer, C. L. (2005). "Information work" and chronic illness: Interpreting results from a nationwide survey of people living with HIV/AIDS. Proceedings of the American Society for Information Science and Technology, 42(1).

Huvila, I. (2009). Ecological framework of information interactions and information infrastructures. Journal of Information Science, 35(6), 695-708.

Johnson, J. D., \& Case, D. O. (2012). Health information seeking. New York: Peter Lang.

Smith, D. E. (2005). Institutional ethnography: A sociology for people. Lanham, MD: Altamira Press.

Sonnenwald, D. H. (1999). Evolving perspectives of human information behavior: Contexts, situations, social networks and information horizons. In T. Wilson \& D. Allen (Eds.), Exploring the contexts of information behaviour (pp. 176-190). London: Taylor Graham.

Souden, M. (2008). Information work in the chronic illness experience. Proceedings of the American Society for Information Science and Technology, 45(1), 1-6.

Star, S. L. (1991). The sociology of the invisible: The primacy of work in the writings of Anselm Strauss. In D. Maines (Ed.), Social organization and social process: Essays in honor of Anselm Strauss (pp. 265-283). Hawthorne, NY: Aldine de Gruyter.

Stooke, R., \& McKenzie, P. J. (2009). Leisure and work in library and community programs for very young children. Library Trends, 57(4), 657-675.

Washington, K. T., Meadows, S. E., Elliott, S. G., \& Koopman, R. J. (2011). Information needs of informal caregivers of older adults with chronic health conditions. Patient Education and Counseling, 83(1), 37-44. 